\title{
VI.-NOTES AND DISCUSSIONS.
}

\section{MR. H. SIDGWICK ON THE CRITICAL PHLOSOPHY.}

A review by $\mathrm{Mr}$. Sidgwick of any philosophical doctrine is sure to contain much of interest for its adherents. His objections, even when directed from the point of view of an outsider, may be taken as fairly indicating some weakness in, or imperfect statement of, the doctrine. In MIND XXIX., he lays before us the first instalment of a comprehensive criticism of the Kantian theory, and those who think that the most valuable philosophic training is to be obtained by the earnest study of that theory, will have an opportunity of judging how a candid inquirer, of independent view, estimates its worth. The introductory article, it is true, does not carry the criticism to the heart of the problem, but it deals with some isolated points of interest and gives a foretaste of the general spirit with which the criticism is animated.

Perhaps it may be allowed to me to say that Mr. Sidgwick's position, so far as can be judged from the article referred to, albeit that of an outsider, seems hardly that of the 'impartial spectator'. Throughout there is a tone of only half-concealed irritation or impatience, evidenced in the ironical compliments to the miscalled "Neo-Kantians"; in the captious remarks on criticism with its small " $c$ "; in the dogmatic utterance respecting Kant's appreciation of his English predecessors; and in the remarkable strength of the epithets applied to some of Kant's positions. At the same time there appears to underlie the whole review a much more definite conception of philosophy generally and of some particular philosophical notions than is compatible with perfect fairness of treatment. The demand that a philosophical analysis of knowledge shall make good its data, its mode of procedure from them and therefore its results, though on the surface formal, may readily and in this case does probably cover a somewhat developed fundamental view. Perhaps it is the presence of some such view that gives to certain statements of Mr. Sidgwick a curiously old-fashioned air. Some criterion is applied the nature of which is not evident on the surface. I am much struck, in this connexion, with Mr. Sidgwick's easy fashion of using and interpreting the data of Common Sense.

Applying his demand regarding the form of a philosophy, Mr. Sidgwick asks what knowledge is accepted by Kant as the presupposition or groundwork of his investigation into the conditions of knowledge. The answer to this being pure mathematics and theoretical physics, so far at least as their fundamental notions are concerned, Mr. Sidgwick, censuring the "Neo-Kantians" for their negligence in omitting to examine the significance of such assumption, proceeds to inquire into its validity. It is with this 
portion of the article that it seems possible to deal in isolation; all the rest, with the possible exception of the critical comments on Kant's arguments respecting Space, is preliminary to the future treatment of the central doctrines.

The argument with respect to these mathematical and physical principles is briefly that Kant's acceptance of them as a basis is illegitimate and inconsistent : for (1) no reason can be given why they should be assumed without inquiry while the notions of theoretical metaphysics are rejected; (2) no valid proof of the principles is possible on the Kantian ground; (3) if their truth be assumed as a matter of Common Sense, Kant contradicts his own contemptuous declarations regarding that philosophic resource, and is, by other doctrines of his own, cut off from its aid. Discussion of these points is rendered very difficult by reason of the ambiguous character of the terms which are, perhaps of necessity, employed by Mr. Sidgwick. " Proved," "valid," and the like, are terms about the significance of which one might argue ad infinitum, and in respect to Kant's doctrine regarding mathematics there is a special and additional source of ambiguity. To prove the validity of the mathematical notions might mean not only to show that these notions have evidence in themselves, that fruitful deductions from them are possible, and that their validity is taken as extending beyond the empirical observations of the thinker who employs them, but to show how such peculiarities are possible. I cannot avoid the reflection that Mr. Sidgwick demands from Kant that as a preliminary for his analysis of experience he shall assume its very results, that acceptance of mathematical notions shall depend upon adequate insight into the grounds of their possibility. Kant's position appears to me sufficiently simple. He takes as empirical marks of mathematical notions, universality and necessity, and no theory respecting the ground of the said marks will alter the nature of the acceptance of them. Apparently Mr. Sidgwick thinks that universality-to take the more patent example-must be based either on absolutely exhaustive survey, or on a theory which shall prove the right to accept part for the whole; from which it follows that, as the first course is impracticable, and the second is the result of the philosophic analysis, universality cannot be assumed at the outset. It appears to me, however, that Kant is right in claiming insight into universality as not merely a quantitative aggregate of separate experiences, but as a qualitative appreciation of the character of the facts experienced. Whatever theory be adopted, the acceptance of such notions as valid for a special order of facts will not be affected; and as mere matter of history, we know that Kant held the same view regarding mathematical notions in conjunction with two quite distinct theories of their possibility.

Mr. Sidgwick's remarks with regard to the rejection of metaphysical notions by Kant do not seem warranted by anything Kant has said. Kant discredits them on the ground that fruitful appli- 
cation of mathematical and physical universals has been made, while no such result has followed in the case of metaphysical notions; but all three are placed on the same footing when an inquiry into the grounds of their possibility is undertaken. Moreover, the criterion, which, as the result of the inquiry, is applied to distinguish metaphysical from mathematico-scientific notions, does not bear upon the conceptual evidence or even self-evidence of these principles, but on the possibility of realising them in experience. In other words, the theorems of metaphysics are not proved false, but unreal.

Mr. Sidgwick, however, thinks that the criterion is in itself insufficient, and accordingly enters on a somewhat elaborate examination of Kant's theory of mathematical evidence. I find it difficult to follow the reasoning; for Mr. Sidgwick seems to me to overlook certain characteristic features of Kant's method, e.g., the distinction between notion and intuition, and the intermediate place occupied by the schema. It follows from the first that we are not to identify truth and reality; from the second, that we are not to regard the realisation of a rule of construction as a perceived fact. The schema is at once concrete and individual, and yet not an empirical fact, a matter of observation. Perhaps it is because Mr. Sidgwick regards the mathematical intuition as a single, definite object, and not as a schema, that he is so astounded and indignant at Kant's expressions in regard to Algebraic processes. He evidently thinks that the intuition required by Kant is to be found only in the letters and signs of operation by which these processes are represented. Kant's brief expressions are sufficiently careless, but they are only directed towards the statement, that the intuitive character of all generation of quantities is additionally evidenced by the fact that where the intuition is not a quantum but quantitas generally, we nevertheless preserve the reference to intuition by employing signs of operations in intuition, signs for subtracting, equating and the like. These symbols are not, as in the case of geometrical schemata, resembling specimens, but representations of general rules of construction in intuition. I can hardly think that $\mathrm{Mr}$. Sidgwick is serious in supposing that it is only because we write algebraic symbols on paper that algebraic processes are assimilated by Kant to geometrical. Mr. Sidgwick appears to hold that algebraic reasoning is distinguished from reasoning in abstract, i.e., from analysis of notions, simply by superior definiteness of the conceptions. I think he will probably find that the definiteness of conception here implies reference to intuition, although a "concrete and individual " image need not be present. Surely Mr. Sidgwick would not suppose that reasoning about a triangle is in concreto while reasoning about a chiliagon is in abstracto. If so, he has misconstrued a fundamental Kantian distinction.

Supplementary arguments are added respecting Arithmetic and its synthetical character. With respect to one of these (p. 79), it may be remarked that, even though time be involved in the 
elementary process on which counting is based, it does not follow that the notion of time should present itself as an integral part of each arithmetical quantity. It is always we who count and yet the notion of ourselves is not part of each arithmetical notion. The other argument is a repetition of an old discussion respecting the well known $7+5=12$. Mr. Sidgwick thinks this not synthetical, on the ground that $7+5=12$ is deducible from $12=7+5$, that this again is deducible from strictly analytical propositions by reversing the statement of the generation of numbers up to 12 , and adding the axiom, itself analytical, that a whole is equal to the sum of its parts "taken in any order". On all this it is sufficient to say that the difference of view rests upon overlooking the reference to intuition which is for Kant the mark of a synthetical proposition, that reversal of the series of numbers is only possible on ground of the previous series of syntheses by which they have been generated, and that an axiom which explicitly contains the mark of intuition-" taken in any order "- can hardly be declared analytical in Kant's sense of that term. The whole matter of this proposition is well discussed in the older books on Kant and in Riehl, whose treatment is very careful.

Turning then to the universals of physical science, Mr. Sidgwick finds that these are accepted by Kant, apparently on the ground that experience confirms them. But according to this very Kant, experience cannot prove such statements, and if they are taken as dictates of Common Sense, it is forgotten that many philosophers have questioned their validity. Here we have the old ambiguity regarding the term prove. Kant's position, I take it, was a very simple one. He finds that in all scientific investigation, in every experiment or observation, certain rules are implied, of scope such that comparison of individual cases cannot be accepted as their basis, and by means of which progress in knowledge is made. The existence of such principles calls for a theory of knowledge which shall offer some explanation, positive or negative, of their ground. The 'safety and certainty' of the physical principles is the condition of no proposition in the theory of knowledge itself.

As to the remaining argument, bringing Kant's expressions before the bar of Common Sense, it has not to my mind any special pertinence. I cannot speak so unhesitatingly as Mr. Sidgwick does regarding Common Sense, which as a rule is wholly unaware of the significance of its own dicta and therefore liable to a distracting diversity of interpretation. In philosophical matters, it probably signifies the sum of what a thinker takes to be true, without being able to render a reason therefor.

It is only right to add that $\mathrm{Mr}$. Sidgwick most fully acknowledges that the central doctrines of the Kritik are not dependent on the acceptance, in one sense or another, of these mathematical and physical principles. His discussion of them, therefore, stands on its own ground, and is to be taken as a mere criticism 
of Kant's power of dealing with isolated questions. In themselves they appear to me to have only historical importance, and I cannot but think that "Neo-Kantians," as Mr. Sidgwick insists on calling them, do well not to embrangle the exposition of Kant's 'new way of ideas' with an extensive discussion, the very significance of which only becomes apparent in the course of working out the 'new way'. A thinker rarely starts from the logical ground of his theory, and it is, moreover, the very peculiarity of philosophy that it does and must return upon its presuppositions and infuse into them a new significance.

R. Adamson.

\section{KANT'S THEORY OF MATHEMATICS.}

Though it is usual to allow a critic to complete his criticisms before offering any comment on them, I ask permission to depart from this course as regards one point in Mr. Sidgwick's " Criticism of the Critical Philosophy" in MIND XXIX., for two reasons: first, because Mr. Sidgwick may perhaps be able to clear up my difficulties before the conclusion of his series of papers; and, secondly, because it seems to me to be of the utmost importance to Philosophy-especially when the Kantian Philosophy is under discussion - that the true nature of Mathematics and Mathematical reasoning should be understood.

Mr. Sidgwick substantially accepts Kant's views as regards Geometry. He differs from the great Critic as regards Arithmetic and Algebra, which are two branches of the Science of Number but which evidently do not exhaust that science though Kant has not in terms referred to Trigonometry, the Differential Calculus, \&c. Mr. Sidgwick's objections to the Kantian theory of the Science of Number appear to be two: (1) that the symbolic construction of concepts in Algebra is not essentially different from the symbolic construction of concepts by means of verbal or written signs in Philosophy; and (2) that Arithmetic does not contain synthetical judgments as Geometry does.

To take the last of these objections first, Kant was not bound to prove that $7+5=12$ is a synthetical judgment. He admits that there are analytical judgments in Arithmetic and Algebra, and if he made a blunder in selecting an example of a synthetical judgment it does not affect his general theory. I do not indeed admit the blunder; but if the existence of synthetical judgments in the Science of Number must be conceded, the question as regards $7+5=12$ is hardly worth debating. Will Mr. Sidgwick maintain that such propositions as $a b=b a$ (or, in its arithmetical expression, in multiplication it is indifferent which number we take as multiplicand and which as multiplier), Newton's Binomial Theorem, Taylor's Theorem or De Moivre's Theorem are analytical propositions? Or that though they are themselves 